\title{
Wastewater-Based Epidemiology as a New Tool for Estimating Population Exposure to Phthalate Plasticizers
}

\author{
Iria González-Mariño,*i) Rosario Rodil, Iván Barrio, Rafael Cela, and José Benito Quintana*(i)
}

Department of Analytical Chemistry, Nutrition and Food Sciences, IIAA - Institute for Food Analysis and Research, University of Santiago de Compostela, Constantino Candeira S/N, 15782 Santiago de Compostela, Spain

\section{Supporting Information}

\begin{abstract}
This study proposes the monitoring of phthalate metabolites in wastewater as a nonintrusive and economic alternative to urine analysis for estimating human exposure to phthalates. To this end, a solid-phase extraction-liquid chromatography-tandem mass spectrometry method was developed, allowing for the determination of eight phthalate metabolites in wastewater (limits of quantification between 0.5 and $32 \mathrm{ng} \mathrm{L^{-1 }}$ ). The analysis of samples from the NW region of Spain showed that these substances occur in raw wastewater up to ca. $1.6 \mu \mathrm{g} \mathrm{L}^{-1}$ and in treated wastewater up to ca. $1 \mu \mathrm{g} \mathrm{L}^{-1}$. Concentrations in raw wastewater were converted into levels of exposure to six phthalate diesters. For two of them, these levels were always below the daily exposure thresholds recommended by the U.S. Environmental Protection Agency and the European Food Safety Authority. For the other four, however, estimates of exposure surpassed such a threshold (especially the toddler threshold) in some cases, highlighting the significance of the exposure to phthalates in children. Finally, concentrations in wastewater were also used to estimate metabolite concentrations in urine, providing a reasonable concordance between our results and the data obtained in two previous biomonitoring studies.
\end{abstract}

\section{INTRODUCTION}

Disubstituted phthalate esters (phthalate diesters or just phthalates) are high-production-volume chemicals that have been widely used in the manufacturing and processing of plastics for more than 80 years. They are added as solubilizing and stabilizing agents to a huge variety of products such as furnishing materials, detergents, lubricants, adhesives, pesticides, textiles, food packages, personal care products, pharmaceuticals, and even medical devices. ${ }^{1}$ Following this widespread utilization, and because they are used as additives (i.e., not chemically bound to containing materials), their easy migration into the environment derives in a continuous exposure to the more-volatile and low-molecular-weight phthalates through inhalation and dermal contact, respectively. ${ }^{2}$ However, ingestion is considered the major route of exposure to phthalates, either by consuming contaminated food, accidental ingestion of contaminated dust and soil, or licking of products in which they are contained (e.g., by babies). ${ }^{3}$ As known endocrine-disrupting (antiandrogenic) compounds, phthalates have shown to speed up and delay pubertal onset in girls and boys, respectively, and to play a role in the manifestation of children obesity. ${ }^{4}$ Childhood exposure is also associated with asthma and allergic symptoms, hypertension, and learning and behavioral problems. In adults, they mainly affect sex-hormone levels, impairing semen quality and causing infertility and gynecological disorders. Additionally, they have been linked to respiratory problems, type 2 diabetes, and pregnancy-induced hypertension. ${ }^{4,5}$ Finally, and although the association of prenatal exposure with birth outcomes is a controversial issue, most studies associate prenatal exposure to phthalates with developmental toxicity (lower rate of weight gain and shorter birth weight and length), neurotoxicity, shorter pregnancy duration, and preterm birth. ${ }^{4,6}$ In view of all these effects, phthalates have been included in the priority lists of dangerous substances in most of the industrialized countries. ${ }^{7-9}$ Oral reference doses $(\mathrm{RfD})^{10-14}$ and tolerable daily intakes (TDI $)^{15-17}$ have been provided for some of them by the U.S. Environmental Protection Agency (EPA) and the European Food Safety Authority (EFSA), respectively.

Once in the human body, phthalates are hydrolyzed to their corresponding monoesters and excreted in a such form or further oxidized and excreted afterward. Both types of metabolites can also be conjugated into glucuronide complexes prior to excretion, but these forms are rapidly hydrolyzed in wastewater by the action of $\beta$-glucuronidase enzymes produced by fecal bacteria. ${ }^{18}$ Since $2000,{ }^{19}$ several studies have been conducted worldwide to assess daily intake levels of phthalates by measuring the concentrations of their metabolites in urine. $^{20-23}$ Although useful, this approach is restricted to a

Received: November 7, 2016

Revised: February 27, 2017

Accepted: February 27, 2017

Published: February 27, 2017 
Table 1. Phthalate Diesters and Monoesters Considered in the Study; Monoester Molar Excretion Fractions (In 24 h, Relative to the Parent Diester Dose) and Correction Factors (CF) Applied to Convert Monoester Excretion Loads in Loads of Exposure to Phthalate Diesters ${ }^{a}$

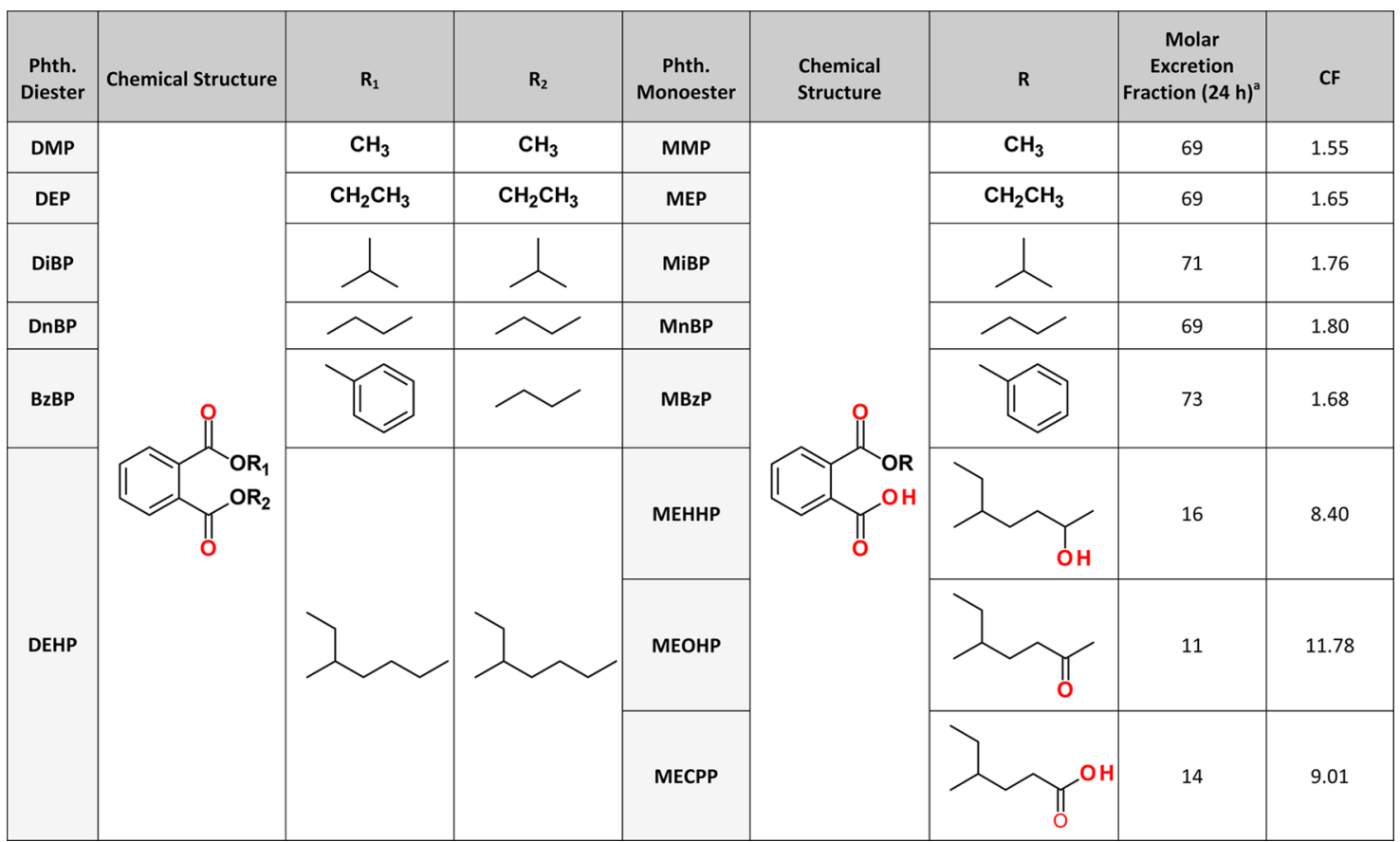

${ }^{a}$ Further details concerning calculations of average excretion fractions and CFs are displayed in Tables S3 and S4.

limited set of samples and, therefore, to a limited number of people. Instead, and assuming that raw wastewater is a highly diluted urine sample of an entire community, levels of a substance in it can be correlated with the consumption and exposure of and to the aforementioned substance in the investigated community. ${ }^{24}$ This methodology, called wastewater-based epidemiology (WBE), has already provided successful results for comparing the consumption of illicit drugs in different countries. ${ }^{25,26}$ Additionally, it has been extended to other stimulant and psychoactive substances such as caffeine, ${ }^{27}$ nicotine, ${ }^{27,28}$ alcohol, ${ }^{29,30}$ and pharmaceuticals. ${ }^{31}$ Besides these applications to self-consciously consumed substances, some studies have recently expanded the WBE approach to estimate the exposure and the effects of exposure to undesired chemicals, such as pesticides ${ }^{32}$ or an oxidative stress biomarker used as an indicator of overall population health status. ${ }^{33}$

Following this trend, this study aims to develop and apply a WBE-method to estimate the exposure to six of the most frequently used phthalate diesters (dimethyl phthalate (DMP), diethyl phthalate (DEP), di- $n$-butyl phthalate (DnBP), di-isobutyl phthalate (DiBP), benzyl butyl phthalate (BzBP), and di(2-ethylhexyl) phthalate (DEHP)) by the analysis of their hydrolyzed metabolites in wastewater. ${ }^{34-36}$ To the best of authors' knowledge, this is the first time that the presence of phthalate monoesters in wastewater is used to estimate exposure to phthalate plasticizers. In fact, only three studies so far have considered the determination of phthalate metabolites in the aqueous environment ${ }^{37,38}$ or in wastewater ${ }^{39}$ but without involving any kind of WBE application.

\section{EXPERIMENTAL SECTION}

Chemicals and Reagents. Phthalate diesters and monoesters considered in the study are displayed in Table 1. DMP,
DEP, DnBP, BzBP, and DEHP were purchased from SigmaAldrich (Steinheim, Germany). The metabolites monomethyl phthalate (MMP), monoethyl phthalate (MEP), mono-n-butyl phthalate $(\mathrm{MnBP})$, and monobenzyl phthalate $(\mathrm{MBzP})$ were purchased from AccuStandard (New Haven, CT, USA). Monoi-butyl phthalate (MiBP), mono-(2-ethylhexyl) phthalate (MEHP), mono-(2-ethyl-5-hydroxyhexyl) phthalate (MEHHP), mono-(2-ethyl-5-oxohexyl) phthalate (MEOHP), mono-(2-ethyl-5-carboxypentyl) phthalate (MECPP), and the deuterated species monomethyl phthalate-D4 (MMP-D4), mono- $n$-butyl phthalate-D4 (MnBP-D4), and mono-(2-ethyl5-hydroxyhexyl) phthalate-D4 (MEHHP-D4) were purchased from TRC (Toronto, ON). Mixed-stock solutions containing $10 \mu \mathrm{g} \mathrm{mL}^{-1}$ of all of the analytes or all the deuterated analogs were prepared in methanol $(\mathrm{MeOH})$ and stored in the dark at $-20{ }^{\circ} \mathrm{C}$.

High-performance liquid chromatography (HPLC)-grade $\mathrm{MeOH}$, acetonitrile (ACN), acetic acid (100\%), hydrochloric acid (37\%), and ammonium acetate $(\geq 98 \%)$ were purchased from Merck (Darmstadt, Germany). Formic acid (95-97\%) was purchased from Sigma-Aldrich (San Luis, MI). Ultrapure water was obtained in the laboratory by purifying demineralized water in a Milli-Q Gradient A-10 system (Merck-Millipore, Bedford, MA).

Wastewater Sampling and Sample Treatment. Wastewater samples were collected at six wastewater treatment plants (WWTPs) from the coastal NW region of Spain; all of them treat mostly domestic wastewater and serve a population between 12000 and 136000 inhabitants. In the plant with the greatest capacity (136000), grab samples of both treated and raw wastewater were taken in March and April 2015. Samples of $24 \mathrm{~h}$ composite raw wastewater were collected for 7 consecutive days in April 2016 from 10:00 a.m. of one day to 10:00 a.m. of the following day. In the remaining plants, $24 \mathrm{~h}$ 
composite samples of treated and raw wastewater were taken for 1 day in June 2016. In all cases, samples were collected by automatic samplers operating in time proportional mode. Exact date, location, population and particular characteristics of the sampling mode are displayed in Table S1. In all cases, samples were transferred to the laboratory and extracted within $8 \mathrm{~h}$ after the end of the sampling.

Under final working conditions, $100 \mathrm{~mL}$ of water was subsequently filtered through $1.6 \mu \mathrm{m}$ glass microfiber filters GF/A (Whatman, Kent) and $0.45 \mu \mathrm{m}$ mixed cellulose acetate and cellulose nitrate filters (Millipore, Bedford, MA), acidified to $\mathrm{pH} 2.0$ with $37 \% \mathrm{HCl}$ and spiked with $50 \mathrm{ng}$ of IS. Next, they were solid-phase extracted (SPE) on Oasis HLB-60 mg cartridges (Waters Corp., Milford, MA), previously rinsed with $3 \mathrm{~mL}$ of $\mathrm{MeOH}$ and $3 \mathrm{~mL}$ of $\mathrm{pH} 2.0$ ultrapure water. Sorbents were dried under nitrogen for $30 \mathrm{~min}$ and analytes eluted with $5 \mathrm{~mL}$ of $\mathrm{MeOH}$. Eluates were concentrated down to $\sim 0.5 \mathrm{~mL}$ under nitrogen (99.999\%) in a Turbovap II concentrator (Zymark, Hopkinton, MA) and diluted to a final volume of 1 $\mathrm{mL}(\mathrm{MeOH})$ for their liquid chromatography-tandem mass spectrometry (LC-MS/MS) analysis. Every sample was processed and analyzed in triplicate.

Liquid Chromatography-Tandem Mass Spectrometry. A total of $10 \mu \mathrm{L}$ of the extracts (or the standards) were injected into a Varian HPLC system (Walnut Creek, CA) equipped with a vacuum degasser, two high-pressure mixing pumps Varian ProStar-210, an automatic sampler Varian ProStar-410 and a thermostated LC column compartment kept at $40{ }^{\circ} \mathrm{C}$. Analyte separation was carried out on a Luna Phenyl-Hexyl column $(150 \times 2 \mathrm{~mm} \mathrm{ID}$, particle size $3 \mu \mathrm{m})$ from Phenomenex (Torrance, CA) using a dual eluent system of (A) $0.1 \%$ acetic acid in ultrapure water and (B) $0.1 \%$ acetic acid in $\mathrm{MeOH}$. The flow rate was set at $200 \mu \mathrm{L} \mathrm{min} \mathrm{min}^{-1}$ and the elution gradient was as follows: $0 \mathrm{~min}(60 \% \mathrm{~B}), 10 \mathrm{~min}(80 \%$ B), $10.5 \min (100 \% \mathrm{~B}), 15.5 \mathrm{~min}(100 \% \mathrm{~B}), 15.6 \mathrm{~min}(60 \% \mathrm{~B})$, $20 \min (60 \% \mathrm{~B})$.

The HPLC system was coupled to a triple quadruple mass spectrometer Varian 320-MS equipped with an electrospray ion source (ESI) operating in negative mode. Nitrogen, used as drying and nebulizing gas, was provided by a nitrogen generator (Erre Due srl, Livorno, Italy). Argon, for the collision induced dissociation, was purchased from Praxair (Madrid, Spain). Working parameters were set at: $4000 \mathrm{~V}$ (needle voltage), 50 ${ }^{\circ} \mathrm{C}$ (source temperature), $200{ }^{\circ} \mathrm{C}$ (drying gas temperature), 18 psi (drying gas pressure), 55 psi (nebulizing gas pressure) and 2.0 mTorr (collision gas pressure). The MS system was operated in Selected Reaction Monitoring (SRM) mode recording one (IS) or two (analytes) precursor/product ion transitions per compound. Transitions, together with chemical formulas, retention times, collision energies (CE) and capillary voltages $(\mathrm{CV})$ are displayed in Table S2.

Method Validation. Analytes were quantified using deuterated compounds as surrogate or internal standards (IS). Only three deuterated analogs (MMP-D4, MnBP-D4, and MEHHP-D4) were used among the eight phthalate monoesters included in the study. Therefore, for the remaining ones, the closest structural or retention time-related deuterated substance was selected as IS (Table S2). Calibration curves were prepared in $\mathrm{MeOH}$ and linearity was evaluated between 1 and $500 \mu \mathrm{g} \mathrm{L}^{-1}$ (IS level: $50 \mu \mathrm{g} \mathrm{L}^{-1}$ ). Instrumental quantification limits (IQL) were calculated from the lowest calibration standards as the concentrations providing a signalto-noise ratio $(\mathrm{S} / \mathrm{N})$ of 10 . Limits of quantification of the whole method (MQL) were estimated in the same way by analyzing extracts of wastewater samples containing low concentrations of all the analytes and $50 \mu \mathrm{g} \mathrm{L}^{-1}$ of IS. Instrumental repeatability was assessed as the relative standard deviation (\%RSD) of five repeated injections of a $50 \mu \mathrm{g} \mathrm{L}^{-1}$ standard (IS level: $50 \mu \mathrm{g}$ $\left.\mathrm{L}^{-1}\right)$. Instrumental reproducibility was assessed as the \%RSD of $50 \mu \mathrm{g} \mathrm{L}^{-1}$ standards (IS level: $50 \mu \mathrm{g} \mathrm{L}^{-1}$ ) analyzed throughout 9 months.

The evaluation of the trueness and precision was performed by recovery studies performed in ultrapure and raw wastewater. Samples of $100 \mathrm{~mL}$ were spiked with $0.5 \mu \mathrm{g} \mathrm{L}^{-1}$ of IS and 0.1 or $1 \mu \mathrm{g} \mathrm{L}^{-1}$ of the analytes (ultrapure water) or $2 \mu \mathrm{g} \mathrm{L}^{-1}$ of the analytes (wastewater) and processed in triplicate. Ionization matrix effects were assessed by comparing the response of a raw wastewater extract spiked with $100 \mu \mathrm{g} \mathrm{L}^{-1}$ of analytes and $50 \mu \mathrm{g}$ $\mathrm{L}^{-1}$ of IS to that of a standard of the same concentration in $\mathrm{MeOH}$. IS-only spiked aliquots were analyzed simultaneously to correct for the background levels of the analytes in wastewater. In all cases, analyses were conducted in triplicate.

Blank Evaluation and Quality Control. Potential contamination issues were assessed both at the sample preparation stage and during the LC-MS analysis by (i) processing Milli-Q aliquots spiked with IS and analyzing them normally (procedural blank); and (ii) analyzing standards containing only IS (analysis blank). A procedural blank and an analysis blank were run simultaneously together with every set of samples. In most cases, a high and very-variable signal was found for MEHP (Figure S1), what lead us to exclude it from the final method. For the remaining analytes, when concentrations in any of the blanks were $>$ IQL or $>$ MQL, these values were subtracted from the levels found in samples.

Stability Tests. Metabolite stability was tested through triplicate experiments designed to assess (i) their potential formation in wastewater from the also occurring parent phthalate diesters; (ii) their potential degradation in this matrix; and (iii) possible losses during filtration.

In the first case, $10 \mathrm{~mL}$ aliquots of raw wastewater were spiked with $0.5 \mathrm{mg} \mathrm{L}^{-1}$ of DMP, DEP, DnBP, BzDP, and DEHP and stored in amber glass vials for $24 \mathrm{~h}$ under different conditions: room temperature $\left(22 \pm 2{ }^{\circ} \mathrm{C}\right)$ and $4{ }^{\circ} \mathrm{C}$, natural $\mathrm{pH}$, and $\mathrm{pH} 2.0(n=3$ in every case). Aliquots of $1 \mathrm{~mL}$ were taken at the beginning of every experiment (time 0 ) and after $1.5,3,5,8$, and $24 \mathrm{~h}$, filtered through $0.45 \mu \mathrm{m}$ mixed cellulose acetate and cellulose nitrate syringe filters, and injected $(10 \mu \mathrm{L})$ into the LC-MS system. Metabolite degradation was assessed in a similar way by spiking $10 \mathrm{~mL}$ of wastewater samples (acidified to $\mathrm{pH} \mathrm{2}$ ) with $0.5 \mathrm{mg} \mathrm{L}^{-1}$ of the eight phthalate monoesters and keeping them at room temperature for $48 \mathrm{~h}(n=3)$. Finally, filtration losses were evaluated by comparing the signal of $0.5 \mathrm{mg} \mathrm{L}^{-1}$ standards with that of ultrapure water samples spiked at the same concentration and filtered afterward as detailed in the Wastewater sampling and sample treatment subsection $(n=3)$.

Estimation of Human Exposure to Phthalate Diesters and Back-Calculation of Monoester Metabolite Concentrations in Urine. Phthalate monoester concentrations in $24 \mathrm{~h}$ composite influent samples were multiplied by wastewater daily flow rates $\left(\mathrm{L} \mathrm{day}^{-1}\right)$ and divided by WWTP served populations (inhabitants, inh) to get monoester excretion loads in $\mu \mathrm{g} \mathrm{day}^{-1}$ inh $^{-1}$. These values were further used to estimate two values; firstly human exposure to phthalate diesters (DMP, DEP, DiBP, DnBP, BzBP, and DEHP). To this end, monoester excretion 
loads were multiplied by the corresponding correction factors (CF, Table 1), calculated according to the following equation:

$$
\mathrm{CF}=\frac{M_{\text {phthalate }} / M_{\text {metabolite }}}{\text { molar excreted fraction }}
$$

where $M_{\text {phthalate }}$ is the molecular weight of the parent phthalate diester; $M_{\text {metabolite }}$ is the molecular weight of the phthalate monoester; and molar excreted fraction is the average molar fraction of the parent compound excreted as that particular metabolite. Average excretion fractions were obtained by weighting the excretion fractions published up to date in human metabolism studies by the number of participants involved in every study (see Tables S3 and S4). Exposure to DEHP was back-calculated from single MEHHP, MEOHP, and MECPP excretion loads (applying individual CFs, Table 1), and the average exposure value was obtained. MnBP excretion load was considered to come entirely from the metabolization of DnBP, and so the contribution of BzBP (for which it is also a minor metabolite, excreted as a $6 \%$ of the phthalate diester dose) was considered negligible. ${ }^{40}$

Secondly, loads were used to estimate the average phthalate monoester concentration in urine per individual (in $\mu \mathrm{g} \mathrm{L}^{-1}$ ), considering a daily urine volume of $1.57 \mathrm{~L}$ per person. This value was obtained by weighting the average daily urine volume provided in three different studies ${ }^{41-43}$ by the number of subjects involved in every study.

\section{RESULTS AND DISCUSSION}

LC-MS/MS Optimization and Validation. Tandem mass spectrometry (MS/MS) conditions (precursor and product ions, $\mathrm{CE}$ and $\mathrm{CV}$ ) were optimized by direct infusion of individual solutions $\left(2 \mathrm{mg} \mathrm{L}^{-1}\right)$ in $\mathrm{MeOH} /$ ultrapure water (1:1). Ionization was performed in negative mode, and two SRM transitions (one precursor and two product ions) were acquired per analyte (Table S2). The most-common products for all the analytes are the ions $m / z 134, m / z 121$, and $m / z 77$, which correspond to (i) the loss of the carboxylic ester group, including the alkyl chain, either completely $(\mathrm{m} / \mathrm{z} 121)$ or retaining the first carbon $(\mathrm{m} / z \mathrm{134})$; and (ii) the additional loss of the ester group, retaining the benzyl anion $(m / z 77)$. For MEHHP, MEOHP, and MECPP, products corresponding to the alkyl cleavage are also obtained. ${ }^{44}$

The effect of several mobile-phase modifiers (formic acid: 0$0.5 \%$; acetic acid: $0-0.5 \%$ and ammonium acetate: $0-25 \mathrm{mM}$ ) was also evaluated by direct injection: higher responses were achieved with acetic acid (data not shown), which was finally added to both the aqueous and the organic phase at a concentration of $0.1 \%$. Also, two different columns of the same dimensions (Luna C18 and Luna Phenyl-Hexyl, both from Phenomenex) and two mobile-phase combinations (ultrapure water- $\mathrm{MeOH}$ and ultrapure water-ACN, both with $0.1 \%$ acetic acid) were considered for the chromatographic separation. As can be seen in Figure S2, isomer separation (MiBP and MnBP) improved on the Phenyl-Hexyl column and by using $\mathrm{MeOH}$. Thus, such conditions were selected to continue with the study.

LC-MS performance parameters (linearity, IQL, instrumental repeatability, and reproducibility) are displayed in Table S2. The representation of the ratio analyte area/surrogate area versus analyte concentration $\left(1-500 \mu \mathrm{g} \mathrm{L}^{-1}\right.$ range) fitted a linear model with determination coefficients $\left(R^{2}\right)$ ranging from 0.9986 to 0.9995 . IQL values varied between 0.01 and $0.31 \mu \mathrm{g}$
$\mathrm{L}^{-1}$; \%RSD values varied between 1.7 and $4.4 \%$ for five repeated injections of a $50 \mu \mathrm{g} \mathrm{L}^{-1}$ standard and between 2.3 and $7.0 \%$ for five $50 \mu \mathrm{g} \mathrm{L}^{-1}$ standards analyzed throughout 9 months.

Analyte Stability. Tests to evaluate the potential formation of phthalate monoesters from the parent diesters in wastewater showed that $\mathrm{MnBP}$ and $\mathrm{MBzP}$ were the only ones being formed $>\mathrm{MQL}$, but only at natural $\mathrm{pH}$ and at very low percentages: up to $0.56 \%$ and $0.20 \%$ of the parent molar concentration, respectively, after $24 \mathrm{~h}$ (Figure S3). Considering the lowness of these figures, $\mathrm{MnBP}$ and $\mathrm{MBzP}$ concentrations in wastewater were attributed to human metabolism exclusively and no correction was applied when estimating exposure to $\mathrm{DnBP}$ and BzBP.

Metabolite stability experiments indicated that six out of the eight analytes were fairly stable, and only MEP and MMP levels dropped significantly (up to $35 \%$ and $23 \%$ of the initial concentration, respectively) after $48 \mathrm{~h}$ at room temperature and $\mathrm{pH} 2$ (Figure 1). In the case of $24 \mathrm{~h}$ sampling, used in most of

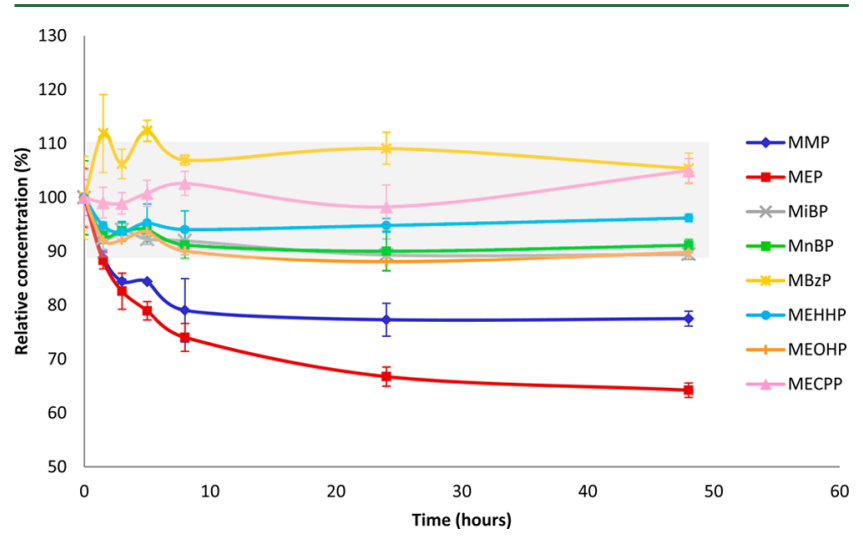

Figure 1. Phthalate monoester stability profiles in wastewater kept at $\mathrm{pH} 2$ and room temperature for $48 \mathrm{~h}$.

the WBE works, the average time the sample spends in the sampling container is $12 \mathrm{~h}$; therefore, the decrease in MMP and MEP is expected to range between 20 and $30 \%$. To minimize such issues, samples were adjusted to $\mathrm{pH} 2$ as soon as received and kept at $4{ }^{\circ} \mathrm{C}$ until extraction (performed within $8 \mathrm{~h}$ ). Finally, no losses were observed during sample filtration (data not shown).

SPE Sorbent Selection and SPE-LC-MS/MS Method Performance. A pair of different sorbents were considered for the SPE: Oasis HLB (polar reversed-phase) and Oasis MAX (mixed mode: polar reversed-phase plus anion exchange). Aliquots $(100 \mathrm{~mL})$ of ultrapure water and raw wastewater were spiked with all the analytes at 1 and $2 \mu \mathrm{g} \mathrm{L}^{-1}$, respectively, and extracted on both sorbents following two different protocols. For the extraction on Oasis HLB, sorbents were conditioned with $3 \mathrm{~mL}$ of $\mathrm{MeOH}$ and $3 \mathrm{~mL}$ of $\mathrm{pH} 2.0$ ultrapure water. Samples were adjusted to $\mathrm{pH} 2$ to neutralize carboxylic groups and favor their retention by reversed-phase interactions. Elution was performed with $5 \mathrm{~mL}$ of $\mathrm{MeOH}$. Oasis MAX cartridges were conditioned with $3 \mathrm{~mL}$ of $0.1 \%$ formic acid in $\mathrm{MeOH}$ followed by $3 \mathrm{~mL}$ of ultrapure water (no $\mathrm{pH}$ adjustment). Samples were passed through them at their natural $\mathrm{pH}(\sim 5.5-$ 7.5 ), and analytes were recovered with $0.1 \%$ formic acid in $\mathrm{MeOH}$. In both cases, extracts were concentrated down to ca. $0.5 \mathrm{~mL}$ and made to a final volume of $1 \mathrm{~mL}$ with $\mathrm{MeOH}$. 
Table 2. Concentrations $\left(\mathrm{ng} \mathrm{L}^{-1}\right)$ in Influent and Effluent Wastewater Samples $(n=3)^{a}$

\begin{tabular}{|c|c|c|c|c|c|c|c|c|c|}
\hline & & MMP & MEP & MiBP & $\mathrm{MnBP}$ & MBzP & MEHHP & MEOHP & MECPP \\
\hline \multirow{2}{*}{ Ares } & $24 \mathrm{~h}$ Effluent & 34 & 22 & 21 & 10 & $<\mathrm{MDL}$ & 96 & 80 & 28 \\
\hline & $24 \mathrm{~h}$ Influent & 92 & 1010 & 185 & 186 & 12 & 36 & 20 & 20 \\
\hline \multirow{2}{*}{ Baiona } & $24 \mathrm{~h}$ Effluent & 41 & 42 & 37 & 52 & $<\mathrm{MDL}$ & $<\mathrm{MDL}$ & $<\mathrm{MDL}$ & $<M D L$ \\
\hline & $24 \mathrm{~h}$ Influent & 146 & 1535 & 277 & 274 & 10 & 31 & 21 & 14 \\
\hline \multirow{2}{*}{ Cambados } & $24 \mathrm{~h} \mathrm{Effluent}$ & 171 & 24 & 25 & 53 & $<M D L$ & 972 & 395 & 227 \\
\hline & $24 \mathrm{~h}$ Influent & 265 & 1599 & 252 & 245 & 19 & 62 & 28 & 26 \\
\hline \multirow{2}{*}{ Gondomar } & $24 \mathrm{~h} \mathrm{Effluent}$ & 68 & 36 & 20 & 12 & $<\mathrm{MDL}$ & $<\mathrm{MDL}$ & $<\mathrm{MDL}$ & $<M D L$ \\
\hline & $24 \mathrm{~h}$ Influent & 48 & 300 & 67 & 55 & 1 & 62 & 34 & 43 \\
\hline \multirow{2}{*}{ Nigrán } & $24 \mathrm{~h}$ Effluent & 351 & $<\mathrm{MDL}$ & 14 & 12 & $<\mathrm{MDL}$ & $<\mathrm{MDL}$ & $<\mathrm{MDL}$ & $<M D L$ \\
\hline & $24 \mathrm{~h}$ Influent & 1885 & 401 & 105 & 59 & $<\mathrm{MDL}$ & 25 & 8 & 8 \\
\hline \multirow{10}{*}{ Santiago } & Grab Effluent & 443 & $<M Q L$ & $<M Q L$ & $<M Q L$ & $<M Q L$ & 12 & 8 & 12 \\
\hline & Grab Influent 1 & 92 & 543 & 146 & 145 & 11 & 18 & 84 & 16 \\
\hline & Grab Influent 2 & 102 & 423 & 111 & 128 & 14 & 19 & $<M Q L$ & 16 \\
\hline & $24 \mathrm{~h}$ Influent 1 & 83 & 567 & 174 & 160 & 12 & 12 & 6 & 10 \\
\hline & $24 \mathrm{~h}$ Influent 2 & 100 & 736 & 129 & 142 & 12 & 11 & 6 & 9 \\
\hline & $24 \mathrm{~h}$ Influent 3 & 115 & 952 & 134 & 147 & 14 & 14 & 8 & 14 \\
\hline & $24 \mathrm{~h}$ Influent 4 & 122 & 737 & 144 & 139 & 12 & 12 & 7 & 8 \\
\hline & $24 \mathrm{~h}$ Influent 5 & 93 & 595 & 113 & 114 & 9 & 84 & 30 & 22 \\
\hline & $24 \mathrm{~h}$ Influent 6 & 127 & 805 & 124 & 145 & 12 & 13 & 6 & 10 \\
\hline & $24 \mathrm{~h}$ Influent 7 & 232 & 1083 & 150 & 163 & 14 & 15 & 10 & 13 \\
\hline
\end{tabular}

$a_{<\mathrm{MDL}}$ : below the method detection limit and, thus, not detected. $<\mathrm{MQL}$ : detected but below the method quantification limit.

Response comparison between these extracts and a standard (for ultrapure water) or an spiked wastewater extract (for wastewater) provided us with the recovery of the SPE process $(n=3)$. Results were similar (and $>80 \%$ ) for seven out of the eight compounds with both sorbents and both matrices. Only MEP showed a lower value in influent wastewater when performing the SPE on Oasis HLB cartridges (77\% versus $106 \%$, Figure S4).

Matrix effects were evaluated for both sorbents by comparing the responses of a spiked-after-the-SPE extract with those of a standard in $\mathrm{MeOH}(n=3)$. The signal suppression observed with Oasis MAX was similar or slightly higher than that observed with Oasis HLB for four out of the eight analytes (Figure S4). For the other four (MMP, MiBP, MnBP, and, especially, MEP) this difference was greater, and so the lower signal suppression got with Oasis HLB, together with the compatibility with the acidification performed to preserve the samples, led us to select it as extraction sorbent.

Once extraction conditions were optimized, trueness and precision of the whole SPE-LC-MS/MS procedure were evaluated through recovery and \%RSD values for triplicate analyses of: (i) ultrapure water $(100 \mathrm{~mL}$ spiked with 0.1 or $1 \mu \mathrm{g}$ $\mathrm{L}^{-1}$ of analytes and $0.5 \mu \mathrm{g} \mathrm{L}^{-1}$ of IS) and (ii) raw wastewater (100 mL spiked with $2 \mu \mathrm{g} \mathrm{L}^{-1}$ of analytes and $0.5 \mu \mathrm{g} \mathrm{L} \mathrm{L}^{-1}$ of IS). Percentages of recovery (\%R) varied between 76 and 124\%; \% RSD values varied between 1.2 and $15 \%$. MQLs were between 0.5 to $32 \mathrm{ng} \mathrm{L}^{-1}$ (see Table S5). All of them were considered acceptable performance figures.

Occurrence of Phthalate Metabolites in Wastewater. Several wastewater samples (both grab and $24 \mathrm{~h}$ composite samples, raw and treated wastewater) were analyzed using the developed methodology. In general, concentrations in effluents were lower than in the corresponding influents (Table 2) except for MMP in Gondomar (68 versus $48 \mathrm{ng} \mathrm{L}^{-1}$ ) and for MEHHP, MEOHP, and MECPP (the three DEHP metabolites) in Ares and Cambados. In this latter case, the concentration increase was remarkably high $(\sim 300-1000 \mathrm{ng}$
$\mathrm{L}^{-1}$ versus $\sim 30-60 \mathrm{ng} \mathrm{L^{-1 }}$ ). This may be attributed to the metabolization, through the activated sludge treatment, of DEHP released from the WWTP. This observation is especially relevant because some phthalate monoesters have shown evidence of being toxic to different organisms. ${ }^{45,46}$

Almost all of the influent samples analyzed exhibited quantifiable concentrations of all the analytes. The highest levels were found for MEP (300-1600 ng L ${ }^{-1}$ ), MMP (48$265 \mathrm{ng} \mathrm{L}^{-1}$ except for Nigrán, where it reached $\left.1800 \mathrm{ng} \mathrm{L}^{-1}\right)$, MiBP (67-277 ng L $\left.\mathrm{L}^{-1}\right)$, and $\mathrm{MnBP}\left(55-274 \mathrm{ng} \mathrm{L} \mathrm{L}^{-1}\right)$. Remaining compounds were below $100 \mathrm{ng} \mathrm{L}^{-1}$ in all cases, with $\mathrm{MBzP}$ showing the lowest maximum concentration (19 ng $\left.\mathrm{L}^{-1}\right)$. Accordingly to what could be expected from their mass excretion fractions (MEHHP: 0.16, MEOHP: 0.11, and MECPP: 0.14 of the DEHP dose), the highest concentrations among these three DEHP metabolites were found for MEHHP in all samples but one (a grab influent sample collected in Santiago). Similarly, the second highest values corresponded to MECPP in 11 out of 15 cases, and MEOHP was quantified, in general, at lower levels.

These results were compared with some of the existing studies, in which the levels of phthalate diesters in Spanish urban wastewaters have been measured. In a review compiled by Bergé et al., ${ }^{47}$ the highest concentrations in wastewater from residential areas were found for DMP (up to $93.3 \mu \mathrm{g} \mathrm{L}^{-1}$ ), followed by DEP (up to $45.9 \mu \mathrm{g} \mathrm{L}^{-1}$ ) and, by far, by DEHP (up to $\left.3.0 \mu \mathrm{g} \mathrm{L}^{-1}\right)$ and $\operatorname{DnBP}\left(2.2 \mu \mathrm{g} \mathrm{L}^{-1}\right)$. BzBP was quantified at levels $<1 \mu \mathrm{g} \mathrm{L}^{-1}$ in all cases. In two studies performed in the same region of the present work (the northwest region of Spain), ${ }^{48,49}$ DMP was, surprisingly, not detected in any sample. DEHP was quantified at the highest levels (up to 6.2 and $1.9 \mu \mathrm{g}$ $\mathrm{L}^{-1}$, respectively) followed by DEP $\left(3.0\right.$ and $\left.0.7 \mu \mathrm{g} \mathrm{L}{ }^{-1}\right)$, DnBP (up to 0.9 and $0.6 \mu \mathrm{g} \mathrm{L}^{-1}$ ) and, finally, BzBP (quantified only in the first study at $0.1 \mu \mathrm{g} \mathrm{L}^{-1}$ ). These values are between 5 and 400 times higher than the maximum concentrations measured for phthalate monoesters in the present study, a fact that contrasts with the closeness of the figures stated in a former 
Table 3. Individual Levels of Exposure to Phthalate Diesters Estimated from Phthalate Monoester Excretion Loads in 24 h Influent Samples ${ }^{a}$

\begin{tabular}{|c|c|c|c|c|c|c|c|c|c|}
\hline \multirow[b]{2}{*}{ average exposure load $\left(\mu \mathrm{g} \mathrm{day}^{-1}\right.$ inhabitant $\left.^{-1}\right)$} & \multirow[b]{2}{*}{ DMP } & \multirow[b]{2}{*}{ DEP } & \multirow[b]{2}{*}{ DiBP } & \multirow[b]{2}{*}{ DnBP } & \multirow[b]{2}{*}{$\mathrm{BzBP}$} & \multicolumn{4}{|c|}{ DEHP based on } \\
\hline & & & & & & МЕHНР & MEOHP & МЕСРP & average \\
\hline Ares & 79 & 926 & 182 & 186 & 11 & 167 & 132 & 101 & 133 \\
\hline Baiona & 92 & 1024 & 198 & 200 & 7 & 105 & 99 & 53 & 86 \\
\hline Cambados & 365 & 2341 & 395 & 392 & 28 & 464 & 288 & 211 & 321 \\
\hline Gondomar & 67 & 449 & 107 & 90 & 2 & 472 & 361 & 352 & 395 \\
\hline Nigrán & 1488 & 336 & 94 & 54 & $<0.12^{b}$ & 108 & 46 & 35 & 63 \\
\hline Santiago & 84 & 559 & 106 & 114 & 10 & 84 & 53 & 48 & 62 \\
\hline weighted average $\left(\mu \text { g day }^{-1} \text { inhabitant }^{-1}\right)^{c}$ & 214 & 714 & 137 & 138 & 10 & 145 & 98 & 83 & 109 \\
\hline $\mathbf{R f D}^{d} / \mathbf{T D I}^{e}\left(\boldsymbol{\mu g} \mathbf{k g}(\mathbf{B W})^{-1} \mathbf{d a y}^{-1}\right)$ & $20^{d}$ & $800^{d}$ & $100^{d} / 10^{e}$ & $100^{d} / 10^{e}$ & $\mathbf{2 0 0} 0^{d} / \mathbf{5 0 0}^{e}$ & \multicolumn{4}{|c|}{$\mathbf{2 0} 0^{d} / \mathbf{5 0}^{e}$} \\
\hline safe reference value $\left(\mu \mathrm{g} \mathrm{day}^{-1} \text { adult }^{-1}\right)^{f}$ & 1416 & 56640 & $7080 / 708$ & $7080 / 708$ & $14160 / 35400$ & \multicolumn{4}{|c|}{$1416 / 3540$} \\
\hline safe reference value $\left(\mu \text { g day }^{-1} \text { toddler }^{-1}\right)^{g}$ & 230 & 9200 & $1150 / 115$ & $1150 / 115$ & $2300 / 5750$ & \multicolumn{4}{|c|}{$230 / 575$} \\
\hline
\end{tabular}

${ }^{a}$ For Santiago, levels were calculated from the average excretion loads of the 7 days. ${ }^{b}$ In Nigrán, the estimated concentration in urine of MBzP was calculated considering a concentration in wastewater equal to $\mathrm{MDL} / 2 .{ }^{c}$ Population-weighted average (considering the six locations). ${ }^{d}$ Oral reference

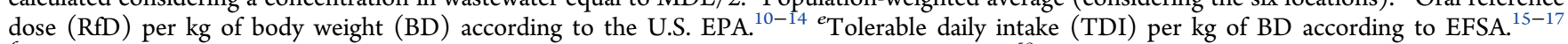

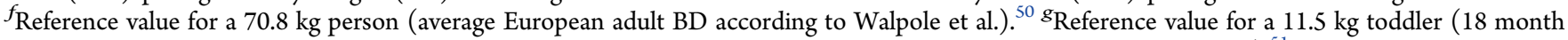
toddler BD was $11.8 \mathrm{~kg}$ for boys and $11.1 \mathrm{~kg}$ for girls, percentile $75 \%$, according to the World Health Organization). ${ }^{51}$

\section{WBE derived values (this work) Herrero et al $2015 \quad$ _ Cutanda et al 2015}

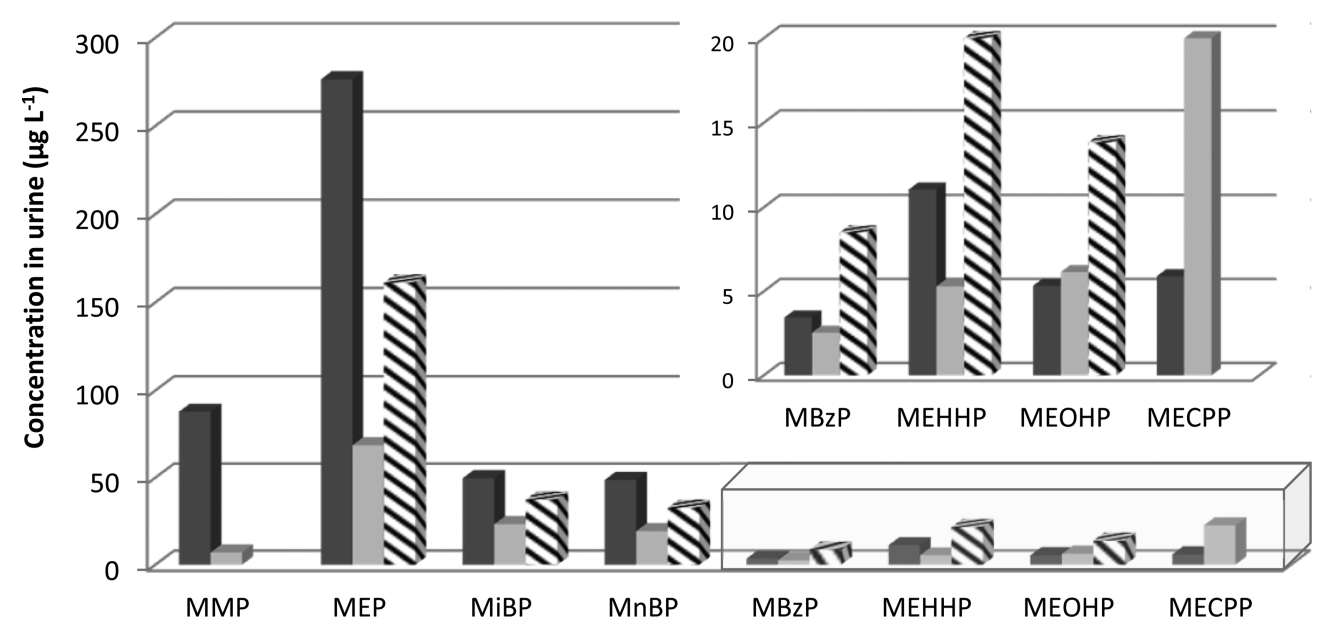

Figure 2. Population-weighted average of phthalate monoester concentrations in urine (estimated by wastewater analysis in this study) versus median of the concentrations found in 21 urine samples from $\operatorname{Spain}^{52}$ and geometric mean of the concentrations measured in urine from 120 Spanish mothers ${ }^{53}$ (see Table S7).

work, in which phthalate diesters and monoesters were quantified in samples from the Tama River (Japan) at levels in the same order of magnitude (between not detected and 1.3 $\mu \mathrm{g} \mathrm{L}^{-1}$ in the case of monoesters, and between not detected and $3.6 \mu \mathrm{g} \mathrm{L}^{-1}$ in the case of diesters). ${ }^{37}$

Phthalate Monoester Excretion Loads from $24 \mathrm{~h}$ Raw Wastewater Analysis: Estimation of Human Exposure to Phthalate Plasticizers. Phthalate monoester concentrations in $24 \mathrm{~h}$ composite influent samples were converted into monoester excretion loads in $\mu \mathrm{g}$ day $^{-1} \mathrm{inh}^{-1}$. These data, together with the average of the seven daily loads calculated for Santiago, were used to perform a pairwise correlation study between all the analytes. Regression coefficients and $p$ values are compiled in Table S6. Significant correlations (for a 95\% of confidence level, $p<0.05$ ) were found between short-chain phthalate monoesters (MEP-MiBP-MnBP-MBzP and $\mathrm{MMP}-\mathrm{MBzP}$ ) and between DEHP metabolites (MEHHPMEOHP-MECPP), suggesting a correlated exposure to shortchain phthalates and independent to DEHP.
Individual levels of exposure were estimated from metabolite excretion loads as detailed in the last subsection of the Experimental section. For DEHP, back-calculations were performed from single MEHHP, MEOHP, and MECPP loads, and the average value was obtained. As expected, the highest exposure was attributed to DEP in all places but Nigrán, where a higher exposure to DMP was observed (Table 3). Because this WWTP was sampled just for 1 day, it is not possible to discern whether this is an abnormal event or a frequent issue concerning DMP in that location. The subsequent highest exposures were attributed to DiBP and DnBP, followed by DMP, DEHP, and, finally, BzBP (lowest). In Santiago, the weekly profile showed no noteworthy variations, except for DEHP, which experienced a remarkable increase on day 5 (see concentrations in Table 2). No clear explanation could be provided.

Population-weighted averages of exposure were calculated for every phthalate taking into account all the locations. Results were compared to the safe reference values obtained using the RfDs provided by the U.S. EPA ${ }^{10-14}$ for phthalate diesters and 
the TDIs provided by EFSA for $\mathrm{DiBP}, \mathrm{DnBP}, \mathrm{BzBP}$, and DEHP. ${ }^{15-17}$ Average adult and toddler body weights were considered to be $70.8^{50}$ and $11.5 \mathrm{~kg}$, ${ }^{51}$ respectively. As displayed in Table 3, levels of exposure to BzBP and DEP were, on average, far below the safe reference values calculated from both RfD and TDI data. Exposure to DEHP surpassed the RfD-derived reference value for toddlers $\left(230 \mu \mathrm{g} \mathrm{day}^{-1}\right)$ in Cambados $\left(321 \mu \mathrm{g} \mathrm{day}^{-1}\right)$ and Gondomar $\left(395 \mu \mathrm{g} \mathrm{day}^{-1}\right)$. For DMP, the reference value-to-weighted average ratio was 6.6 for adults and 1.1 for toddlers, showing the closeness of our estimates to the limit considered as "safe". This particular outcome is clearly affected by the high exposure estimate observed for this compound in Nigrán (higher than the safe reference value for both adults and toddlers), and more samples should be collected and analyzed to confirm and discard such figures. Finally, TDI-derived reference value-to-weighted average ratios for $\mathrm{DiBP}$ and $\mathrm{DnBP}$ were 5.1-5.2 for adults and 0.8 for toddlers, with average exposure estimates above the TDI-derived safe reference value for toddlers in three out of the six places investigated. This observation highlights the significance of children exposure to this plasticizer, which could eventually derive in chronic undesired effects. Thus, WBE may serve as an early warning so that a biomonitoring study on exposure to phthalate diesters can be recommended in specific populations.

Estimation of Phthalate Monoester Concentrations Per Capita in Urine. Finally, phthalate monoester excretion loads were used to estimate average phthalate monoester concentrations in urine (in $\mu \mathrm{g} \mathrm{L}^{-1}$ ) in the studied area (Western of Galicia, northwest region of Spain). To this end, an average daily urine volume of $1.57 \mathrm{~L}$ per person was considered. ${ }^{41-43}$ As shown in Figure 2, the highest populationweighted averages were obtained for MEP $\left(276 \mu \mathrm{g} \mathrm{L}^{-1}\right.$ per person per day), followed by MMP $\left(88 \mu \mathrm{g} \mathrm{L}^{-1}\right)$ and the isomers MiBP and MnBP (50 and $49 \mu \mathrm{g} \mathrm{L}^{-1}$, respectively). $\mathrm{MBzP}$ would be excreted at average levels below $4 \mu \mathrm{g} \mathrm{L}^{-1}$ per person per day, and MEHHP, MEOHP, and MECPP at concentrations of 11,5 , and $6 \mu \mathrm{g} \mathrm{L}^{-1}$ per person per day, respectively. These values were compared to the median and geometric mean values of phthalate monoester concentrations found in real urine in two Spanish studies involving 21 and 120 participants (only female in the latter case), respectively. ${ }^{52,53}$ For MiBP, MnBP, and MEOHP, the highest difference between measured and estimated levels was $<60 \%$. For MEP, MBzP, MEHHP, and MECPP this difference was up to $75 \%$ and for MMP up to $92 \%$ ( 7 versus $88 \mu \mathrm{g} \mathrm{L}^{-1}$ ). Except this compound, for which the concentration in urine estimated from wastewater analysis was the second highest, the three set of values agreed on the pattern of abundance. MEP was the compound eliminated in urine at higher levels, followed by MiBP, $\mathrm{MnBP}$, and MECPP (analyzed only in one of the literature cases $)^{52}$ and then the remaining monoesters. In all cases, MBzP was the one found and estimated at lower concentrations. It must be noted, however, that those studies come from different geographical areas of Spain (Madrid and Toledo) and from a small population or even a subpopulation (pregnant women). ${ }^{52,53}$ Discrepancies between these two works are sometimes higher than the differences found between their figures and our data (Figure 2). Hence, we consider WBE a reliable tool when average exposure is targeted.

Outlook and Future Research Needs. The results shown in this study indicate that WBE is a useful tool for determining phthalate exposure at the population level, therefore complementing other exposure assessments such as urinary metabolite analysis of individuals. WBE can be used as a rapid and inexpensive tool with which to compare temporal and spatial exposure trends and to potentially identify regions where people are most at risk and thus can be used as an early warning system.

Further research in the field will consider, to get representative figures, larger communities sampled for longer sampling periods. ${ }^{54}$ Similarly, further investigation of the insewer stability of phthalates is of interest to fully ensure biomarker stability because some chemicals may be stable in collected wastewater (i.e., not degraded during laboratory stability studies) but undergo transformations in real sewers due to the different biological activity occurring in sewage systems. ${ }^{55}$ In this line, assessing the behavior of phthalate glucuronides in different wastewaters is also necessary to check the real extension of their hydrolysis under different conditions, although preliminary results indicate that it is close to $100 \%$.

\section{ASSOCIATED CONTENT}

\section{S Supporting Information}

The Supporting Information is available free of charge on the ACS Publications website at DOI: 10.1021/acs.est.6b05612.

Tables showing WWTP characteristics, instrumental and method validation parameters, details concerning calculations of average excretion fractions and CFs, regression coefficients and $p$-values for the pairwise correlation study and estimated concentrations of phthalate monoesters in urine. Figures showing a MEHP chromatogram of a procedural blank, isomer separation using different columns and mobile phases, formation of $\mathrm{MnBP}$ and MBzP from their parent diesters and SPE recoveries and matrix effects got with Oasis HLB and Oasis MAX sorbents (PDF)

\section{AUTHOR INFORMATION}

\section{Corresponding Authors}

*Phone: +34 881 816035; e-mail: iria.gonzalez@usc.es.

*Phone: +34 881 814263; e-mail: jb.quintana@usc.es.

\section{ORCID}

Iria González-Mariño: 0000-0002-2846-8380

José Benito Quintana: 0000-0002-2566-8133

\section{Notes}

The authors declare no competing financial interest.

\section{ACKNOWLEDGMENTS}

This work was financed by Spanish Ministry of Economy and Competitiveness (MINECO; project no. CTM2014-56628-C32-R), Xunta de Galicia (GRC2013-020 and IGM postdoctoral contract "Plan Galego de Investigación, Innovación e Crecemento 2011-2015”) and FEDER/ERDF. We also acknowledge Viaqua, Augas de Galicia, Idom, and Indrops for their support in WWTPs sampling.

\section{REFERENCES}

(1) Heudorf, U.; Mersch-Sundermann, V.; Angerer, J. Phthalates: toxicology and exposure. Int. J. Hyg. Environ. Health 2007, 210, 623634.

(2) Gong, M.; Weschler, C. J.; Zhang, Y. Impact of Clothing on Dermal Exposure to Phthalates: Observations and Insights from Sampling Both Skin and Clothing. Environ. Sci. Technol. 2016, 50, 4350-4357. 
(3) Itoh, H.; Yoshida, K.; Masunaga, S. Quantitative identification of unknown exposure pathways of phthalates based on measuring their metabolites in human urine. Environ. Sci. Technol. 2007, 41, 45424547.

(4) Katsikantami, I.; Sifakis, S.; Tzatzarakis, M. N.; Vakonaki, E.; Kalantzi, O. I.; Tsatsakis, A. M.; Rizos, A. K. A global assessment of phthalates burden and related links to health effects. Environ. Int. 2016, 97, 212-236.

(5) Zarean, M.; Keikha, M.; Poursafa, P.; Khalighinejad, P.; Amin, M.; Kelishadi, R. A systematic review on the adverse health effects of di-2ehtylhexyl phthalate. Environ. Sci. Pollut. Res. 2016, 23, 24642-24693.

(6) Wolff, M. S.; Engel, S. M.; Berkowitz, G. S.; Ye, X.; Silva, M. J.; Zhu, C.; Wetmur, J.; Calafat, A. M. Prenatal phenol and phthalate exposures and birth outcomes. Environ. Health Perspect. 2008, 116 (8), $1092-1097$.

(7) European Food Safety Authority. Commission Directive 2007/ 19/EC of 30th March 2007 amending Directive 2002/72/EC relating to plastics materials and articles to come into contact with food and Council Directive 85/572/EEC laying down the list of stimulants to be used for testing migration of constituents of plastic materials and articles intended to come into contact with food stuffs. Off. J. Eur. Commun. 2007, L 91.

(8) U.S. FDA. Phthalates and Cosmetic Products. http://www.fda. gov/cosmetics/productsingredients/ingredients/ucm128250.html (accessed on Feb 09, 2016).

(9) Ministry of Health of Canada. Canada Consumer Product Safety Act. Phthalates regulations. http://laws-lois.justice.gc.ca/eng/ regulations/SOR-2016-188/index.html (Feb 09, 2016).

(10) U.S. Environmental Protection Agency. Chemical Assessment Summary for Dimethyl phthalate; CASRN 131-11-3; U.S. EPA: Washington, DC.

(11) U.S. Environmental Protection Agency. Chemical Assessment Summary for Diethyl phthalate; CASRN 84-66-2; U.S. EPA: Washington, DC.

(12) U.S. Environmental Protection Agency. Chemical Assessment Summary for Dibutyl phthalate; CASRN 84-74-2; U.S. EPA: Washington, DC.

(13) U.S. Environmental Protection Agency. Chemical Assessment Summary for Butyl benzyl phthalate; CASRN 85-68-7; U.S. EPA: Washington, DC.

(14) U.S. Environmental Protection Agency. Chemical Assessment Summary for Di(2-ethylhexyl)phthalate (DEHP); CASRN 117-81-7; U.S. EPA: Washington, DC.

(15) European Food Safety Authority. Opinion of the Scientific Panel on Food Additives, Flavourings, Processing Aids and Material in Contact with Food (AFC) on a request from the Commission related to Di-Butylphthalate (DBP) for use in food contact materials. EFSA Journal 2005, 242, 1-17.

(16) European Food Safety Authority. Opinion of the Scientific Panel on Food Additives, Flavourings, Processing Aids and Material in Contact with Food (AFC) on a request from the Commission related to Butylbenzylphthalate (BBP) for use in food contact materials. EFSA Journal 2005, 241, 1-14.

(17) European Food Safety Authority. Opinion of the Scientific Panel on Food Additives, Flavourings, Processing Aids and Material in Contact with Food (AFC) on a request from the Commission related to Bis(2-ethylhexyl)phthalate (DEHP) for use in food contact materials. EFSA Journal 2005, 243, 1-20.

(18) D’Ascenzo, G.; Di Corcia, A.; Gentili, A.; Mancini, R.; Mastropasqua, R.; Nazzari, M.; Samperi, R. Fate of natural estrogen conjugates in municipal sewage transport and treatment facilities. Sci. Total Environ. 2003, 302 (1-3), 199-209.

(19) David, R. M. Exposure to phthalate esters. Environ. Health Perspect. 2000, 108, A440-A443.

(20) Fromme, H.; Bolte, G.; Koch, H. M.; Angerer, J.; Boehmer, S.; Drexler, H.; Mayer, R.; Liebl, B. Occurrence and daily variation of phthalate metabolites in the urine of an adult population. Int. J. Hyg. Environ. Health 2007, 210, 21-33.
(21) Wittassek, M.; Wiesmuller, G. A.; Koch, H. M.; Eckard, R.; Dobler, L.; Muller, J.; Angerer, J.; Schlüter, C. Internal phthalate exposure over the last two decades: a retrospective human biomonitoring study. Int. J. Hyg. Environ. Health 2007, 210, 319-333.

(22) Koch, H. M.; Wittassek, M.; Brüning, T.; Angerer, J.; Heudorf, U. Exposure to phthalates in 5-6 years old primary school starters in Germany-a human biomonitoring study and cumulative risk assessment. Int. J. Hyg. Environ. Health 2011, 214, 188-195.

(23) Casas, L.; Fernández, M. F.; Llop, S.; Guxens, M.; Ballester, F.; Olea, N.; Irurzun, M. B.; Rodríguez, L. S. M.; Riaño, I.; Tardon, A.; Vrijheid, M.; Calafat, A. M.; Sunyer, J. Urinary concentrations of phthalates and phenols in a population of Spanish pregnant women and children. Environ. Int. 2011, 37, 858-866.

(24) Zuccato, E.; Chiabrando, C.; Castiglioni, S.; Bagnati, R.; Fanelli, $\mathrm{R}$ Estimating Community Drug Abuse by Wastewater Analysis. Environ. Health Persp. 2008, 116, 1027-1032.

(25) Thomas, K. V.; Bijlsma, L.; Castiglioni, S.; Covaci, A.; Emke, E.; Grabic, R.; Hernández, F.; Karolak, S.; Kasprzyk-Hordern, B.; Lindberg, R. H.; López de Alda, M.; Meierjohann, A.; Ort, C.; Picó, Y.; Quintana, J. B.; Reid, M.; Rieckermann, J.; Terzic, S.; van Nuijs, A. L.; de Voogt, P. Comparing illicit drug use in 19 European cities through sewage analysis. Sci. Total Environ. 2012, 432, 432-439.

(26) Ort, C.; van Nuijs, A. L. N.; Berset, J. D.; Bijlsma, L.; Castiglioni, S.; Covaci, A.; de Voogt, P.; Emke, E.; Fatta-Kassinos, D.; Griffiths, P.; Hernández, F.; González-Mariño, I.; Grabic, R.; Kasprzyk-Hordern, B.; Mastroianni, N.; Meierjohann, A.; Nefau, T.; Östman, M.; Picó, Y.; Racamonde, I.; Reid, M.; Slobodnik, J.; Terzic, S.; Thomaidis, N.; Thomas, K. V. Spatial differences and temporal changes in illicit drug use in Europe quantified by wastewater analysis. Addiction 2014, 109, $1338-1352$

(27) Senta, I.; Gracia-Lor, E.; Borsotti, A.; Zuccato, E.; Castiglioni, S. Wastewater analysis to monitor use of caffeine and nicotine and evaluation of their metabolites as biomarkers for population size assessment. Water Res. 2015, 74, 23-33.

(28) Rodríguez-Álvarez, T.; Rodil, R.; Rico, M.; Cela, R.; Quintana, J. B. Assessment of Local Tobacco Consumption by Liquid Chromatography-Tandem Mass Spectrometry Sewage Analysis of Nicotine and Its Metabolites, Cotinine and trans-3'-Hydroxycotinine, after Enzymatic Deconjugation. Anal. Chem. 2014, 86, 10274-10281.

(29) Rodríguez-Álvarez, T.; Racamonde, I.; González-Mariño, I.; Borsotti, A.; Rodil, R.; Rodríguez, I.; Zuccato, E.; Quintana, J. B.; Castiglioni, S. Alcohol and cocaine co-consumption in two European cities assessed by wastewater analysis. Sci. Total Environ. 2015, 536, 91-98.

(30) Ryu, Y.; Barceló, D.; Barron, L. P.; Bijlsma, L.; Castiglioni, S.; de Voogt, P.; Emke, E.; Hernández, F.; Lai, F. Y.; Lopes, A.; de Alda, M. L.; Mastroianni, N.; Munro, K.; O’Brien, J.; Ort, C.; Plósz, B. G.; Reid, M. J.; Yargeau, V.; Thomas, K. V. Comparative measurement and quantitative risk assessment of alcohol consumption through wastewater-based epidemiology: An international study in 20 cities. Sci. Total Environ. 2016, 565, 977-983.

(31) Verlicchi, P.; Al Aukidy, M.; Jelic, A.; Petrovic, M.; Barceló, D. Comparison of measured and predicted concentrations of selected pharmaceuticals in wastewater and surface water: a case study of a catchment area in the Po Valley (Italy). Sci. Total Environ. 2014, 470$471,844-854$.

(32) Rousis, N.; Zuccato, E.; Castiglioni, S. Monitoring population exposure to pesticides based on liquid chromatography-tandem mass spectrometry measurement of their urinary metabolites in urban wastewater: A novel biomonitoring approach. Sci. Total Environ. 2016, 571, 1349-1357.

(33) Ryu, Y.; Reid, M. J.; Thomas, K. V. Liquid chromatographyhigh resolution mass spectrometry with immunoaffinity clean-up for the determination of the oxidative stress biomarker 8-iso-prostaglandin F2alpha in wastewater. J. Chromatogr. A 2015, 1409, 146-151.

(34) Barr, D. B.; Silva, M. J.; Kato, K.; Reidy, J. A.; Malek, N. A.; Hurtz, D.; Sadowski, M.; Needham, L. L.; Calafat, A. M. Assessing human exposure to phthalates using monoesters and their oxidized 
metabolites as biomarkers. Environ. Health Perspect. 2003, 111 (9), $1148-51$.

(35) Kato, K.; Silva, M. J.; Reidy, J. A.; Hurtz, D.; Malek, N. A.; Needham, L. L.; Nakazawa, H.; Barr, D. B.; Calafat, A. M. Mono(2Ethyl-5-Hydroxyhexyl) Phthalate and Mono-(2-Ethyl-5-Oxohexyl) Phthalate as Biomarkers for Human Exposure Assessment to Di-(2Ethylhexyl) Phthalate. Environ. Health Perspect. 2003, 112 (3), 327330.

(36) Koch, H. M.; Preuss, R.; Angerer, J. Di(2-ethylhexyl)phthalate (DEHP): human metabolism and internal exposure-an update and latest results. Int. J. Androl. 2006, 29 (1), 155-65.

(37) Suzuki, T.; Yaguchi, K.; Suzuki, S.; Suga, T. Monitoring of Phthalic Acid Monoesters in River Water by Solid-Phase Extraction and GC-MS Determination. Environ. Sci. Technol. 2001, 35, 37573763.

(38) Blair, J. D.; Ikonomou, M. G.; Kelly, B. C.; Surridge, B.; Gobas, F. A. P. C. Ultra-Trace Determination of Phthalate Ester Metabolites in Seawater, Sediments, and Biota from an Urbanized Marine Inlet by LC/ESI-MS/MS. Environ. Sci. Technol. 2009, 43, 6262-6268.

(39) Kusk, K. O.; Kruger, T.; Long, M.; Taxvig, C.; Lykkesfeldt, A. E.; Frederiksen, H.; Andersson, A. M.; Andersen, H. R.; Hansen, K. M. S.; Nellemann, C.; Bonefeld-Jorgensen, E. C. Endorine potency of wastewater: contents of endocrine disrupting chemicals and effects measured by in vivo and in vitro assays. Environ. Toxicol. Chem. 2011, 30, 413-426.

(40) Anderson, W.; Castle, L.; Scotter, M.; Massey, R. C.; Springall, C. A biomarker approach to measuring human dietary exposure to certain phthalate diesters. Food Addit. Contam. 2001, 18, 1068-1074.

(41) Murakami, K.; Sasaki, S.; Takahashi, Y.; Uenishi, K.; Watanabe, T.; Kohri, T.; Yamasaki, M.; Watanabe, R.; Baba, K.; Shibata, K.; Takahashi, T.; Hayabuchi, H.; Ohki, K.; Suzuki, J. Sensitivity and specificity of published strategies using urinary creatinine to identify incomplete 24-h urine collection. Nutrition 2008, 24, 16-22.

(42) Perinpam, M.; Ware, E. B.; Smith, J. A.; Turner, S. T.; Kardia, S. L. R.; Lieske, J. C. Key influence of sex on urine volume and osmolality. Biol. Sex Differ. 2016, 7 (12), 1-8.

(43) Nabavizadeh, P.; Ghadermarzi, S.; Fakhri, M. New Method to Make 24-h Urine Collection More Convenient: A Validity Study. Int. J. Nephrol. 2014, 2014, 1-5.

(44) Koch, H. M.; Gonzalez-Reche, L. M.; Angerer, J. On-line cleanup by multidimensional liquid chromatography-electrospray ionization tandem mass spectrometry for high throughput quantification of primary and secondary phthalate metabolites in human urine. $J$. Chromatogr. B: Anal. Technol. Biomed. Life Sci. 2003, 784, 169-182.

(45) Heudorf, U.; Mersch-Sundermann, V.; Angerer, J. Phthalates: Toxicology and exposure. Int. J. Hyg. Environ. Health 2007, 210, 623634.

(46) Ye, T.; Kang, M.; Huang, Q.; Fang, C.; Chen, Y.; Shen, H.; Dong, S. Exposure to DEHP and MEHP from hatching to adulthood causes reproductive dysfunction and endocrine disruption in marine medaka (Oryzias melastigma). Aquat. Toxicol. 2014, 146, 115-126.

(47) Bergé, A.; Cladière, M.; Gasperi, J.; Coursimault, A.; Tassin, B.; Moilleron, R. Meta-analysis of environmental contamination by phthalates. Environ. Sci. Pollut. Res. 2013, 20, 8057-8076.

(48) Polo, M.; Llompart, M.; García-Jares, C.; Cela, R. Multivariate optimization of a solid-phase microextraction method for the analysis of phthalate esters in environmental waters. J. Chromatogr. A 2005, 1072, 63-72.

(49) Regueiro, J.; Llompart, M.; García-Jares, C.; GarcíaMonteagudo, J. C.; Cela, R. Ultrasound-assisted emulsificationmicroetraction of emergent contaminants and pesticides in environmental waters. J. Chromatogr. A 2008, 1190 (1-2), 27-38.

(50) Walpole, S. C.; Prieto-Merino, D.; Edwards, P.; Cleland, J.; Stevens, G.; Roberts, I. The weight of nations: an estimation of adult human biomass. BMC Public Health 2012, 12, 439-444.

(51) World Health Organization. WHO Child Growth Standards Length/height-for-age, weight-for-age, weight-for-length, weight-for-height and body mass index-for-age: methods and development; WHO: Washington, DC, 2006.
(52) Herrero, L.; Calvarro, S.; Fernández, M. A.; Quintanilla-López, J. E.; González, M. J.; Gómara, B. Feasibility of ultra-high performance liquid and gas chromatography coupled to mass spectrometry for accurate determination of primary and secondary phthalate metabolites in urine samples. Anal. Chim. Acta 2015, 853, 625-636.

(53) Cutanda, F.; Koch, H. M.; Esteban, M.; Sánchez, J.; Angerer, J.; Castaño, A. Urinary levels of eight phthalate metabolites and bisphenol A in mother-child pairs from two Spanish locations. Int. J. Hyg. Environ. Health 2015, 218, 47-57.

(54) Castiglioni, S.; Bijlsma, L.; Covaci, A.; Emke, E.; Hernández, F.; Reid, M.; Ort, C.; Thomas, K. V.; van Nuijs, A. L. N.; de Voogt, P.; Zuccato, E. Evaluation of Uncertainties Associated with the Determination of Community Drug Use through the Measurement of Sewage Drug Biomarkers. Environ. Sci. Technol. 2013, 47, 14521460.

(55) McCall, A. K.; Bade, R.; Kinyua, J.; Lai, F. Y.; Thai, P. K.; Covaci, A.; Bijlsma, L.; van Nuijs, A. L. N.; Ort, C. Critical review on the stability of illicit drugs in sewers and wastewater samples. Water Res. 2016, 88, 933-947. 